\title{
Strengthening of Concrete Box Girder Bridges under
}

\section{Close-in Detonations}

\author{
Ahmed Ibrahim ${ }^{1}$ and Hani Salim ${ }^{2}$ \\ 1. Department of Civil Engineering and Construction, Bradley University, Peoria IL 61625, USA \\ 2. Department of Civil and Environmental Engineering, University of Missouri, Columbia MO 65211, USA
}

\begin{abstract}
The response of a bridge superstructure under blast loading might depend largely on the extent of the local damage experienced due to close-in explosion threats. This paper investigates the local and structural response of box girder bridge decks strengthened using CFRP (carbon fiber reinforced polymers) under close-in detonations. Due to the lack of experimental research on this topic, the study is conducted using the explicit finite element computer program LS-DYNA. The numerical study will be verified using the results of strengthened reinforced concrete slabs under field detonations. The blast load was assumed to be detonated above the bridge deck. The key parameters investigated are the charge size, and the strengthening location on the deck. This paper will present the results of this investigation and provides recommendations for predicting the local damage level based on the CFRP strengthening design under blast threat.
\end{abstract}

Key words: Pre-stressed, blast, box girder, bridges, carbon fiber.

\section{Introduction}

The National Research Board [1] reports that there are approximately 650,000 structures exist in the National Bridge database in the United States. Many of these structures have exceeded their design life. These factors in conjunction with cyclic loading, deterioration from chlorides used in anti-icing operations, have left many bridges in need of repair, strengthening or replacement. Of this number, approximately $7.7 \%$ are classified as structurally deficient, $14 \%$ are functionally outmoded and $8.5 \%$ are both structurally deficient and functionally out-of-date.

CFRP (carbon fiber reinforced polymer) is considered one of the best retrofitting materials under static loads and it gave good results under blast loads due to strength-to-self-weight ratio and the large fatigue resistance. There are many different various results regarding the behaviour of retrofitted structural components using CFRP but limited research exists for

Corresponding author: Ahmed Ibrahim, $\mathrm{PhD}$, assistant professor, research fields: structural engineering. E-mail: aibrahim@bumail.bradley.edu. the behaviour of these types of material for box girder bridges under blast loads.

The structural behaviour of Horsetail Greek Bridge strengthened by carbon reinforced polymer composites study [2]. The bridge superstructure and the substructure were modelled using the finite element code ANSYS. The bridge was analysed under different truck loading at different locations. The results of the numerical analysis were compared to field data showing good agreement. The results presented in terms of strains in beams. Structural responses were compared for strengthened and un-strengthened bridge using the CFRP, which introduced significant improvement to the structural performance.

The strengthening of the bridge using CFRP based on scaled truck and mass proportional loading increased the capacity by $28 \%$ and $37 \%$ respectively. The CFRP delayed the yielding of the reinforcement and the failure mode changed from sudden shear failure to flexural, which indicates ductility increase due to the CFRP composites.

The transient deformation and blast resistance of unidirectional fiber reinforced composites were studied 
by Betra and Hassan [3]. The unidirectional fibber reinforced layers were assumed perfectly bonded to each other when subject to blast load. The analyses were done using an in-house developed FORTRAN code, the code included the rate dependent damage equations for anisotropic bodies. The relative sliding between layers was modelled using the nodal releases technique. The effect of different materials and the loading parameters on the damage propagation was considered. The goal of the study was to examine the energy absorption and increasing the structural resistance to blast loads when unidirectional fiber reinforced composites was used.

The laminates deformation for close non-nuclear explosives detonations is similar to those induced by the nuclear explosion was concluded [3]. The increase in the fiber volume fraction decreases the total external work done by external forces and hence decrease the kinetic energy which has no effect on the energy required to deform the body.

A state-of-the-art review on blast resistance of FRP (fiber reinforce plastic) composites and polymer strengthened concrete and masonry structures was introduced by Buchan and Chen [4]. The paper presented the latest and up-to-date researches on FRP and the blast effect on masonry walls. The blast resistance can be increased by adding additional concrete mass and reinforcement to the structure but the cost is one of the problems facing this technique. Another solution, is using steel studs walls can be used in the interior face of the walls facing the blast load to increase the ductility and energy absorption. The choice of the retrofitting materials is very important in optimizing the performance and cost. Buchan et al. [4] summarized the material assessed in this approach for beams and slabs subject to high explosives.

The structural behavior of FRP composites bridge deck panels was studied by Alagusundaramoorthy et al. [5]. The study evaluated the force-displacement responses of FRP composites bridge deck panels under
AASHTO MS 22.5 (HS25) truck load up to failure. Many modes of failure were studied including flexural and shear. The test results were compared with the performance criterion of Ohio Department of Transportation, the tested bridge panels gave good results with a safety factor varied from three to eight.

A study [6] on computational model using the finite element method to investigate the nonlinear transient behaviour of reinforced concrete slab subjected to blast loading and retrofitted with CFRP composites. The model was used to investigate the effect of loading duration and the effect of the CFRP on the slabs damage accumulations. The study showed that using of CFRP prevents the total failure of the slab systems against the cracking and crushing of the as-built slabs. The load carrying capacity of the retrofitted slabs was increased by $200 \%$. Retrofitting the two way slab systems by CFRP limited the spread of yielding in the steel reinforcement.

An analytical finite element model for study of FRP retrofitted concrete structures under blast loads was performed [7] to assess and compare a comprehensive finite element model of FRP that can be properly used in the simulation techniques. Four analytical models were tested to assess the behavior of the FRP sheets in retrofitted concrete structures. The models were isotropic linear elastic shell element, orthotropic linear elastic shell elements without shear deformations, orthotropic linear elastic shell elements with shear deformations, and linear elastic beam element model.

\section{Material and Numerical Models}

The box girder bridge was modeled using the nonlinear finite element code [8]. The finite element model of the bridge is shown in Fig. 1. It consists of a regular mesh of hexagonal solid elements of a typical aspect ratio of 1.00. The simply supported bridge was modeled taking the advantage of the symmetry, so only quarter of the bridge was modeled. The boundary conditions along the transverse and longitudinal directions were taken into account as shown in Fig. 2. The high explosive 
material was assumed at a height equals $762 \mathrm{~mm}$ above the bridge deck.

The structural characteristics of reinforced concrete box girder bridges strengthened with CFRP composites under blast loads cannot be easily assessed with simple procedure. Experimental tests, especially in the area of blast load, are very expensive in terms of the number of specimens and the required instrmentation. Numerical study, if properly conducted provides a reliable and trusted assessment of bridge responses. In this section a numerical study is conducted on a number of box girder bridges under blast loads to predict the damage level and the correspoding improvements in the response and performance.

The CFRP composites are used to strengthen the bridge under certain expolsive charge weights. In this study the charge weights are $10 \mathrm{~W}$ and $30 \mathrm{~W}$, and these espolsives were placed over the bridge deck above the

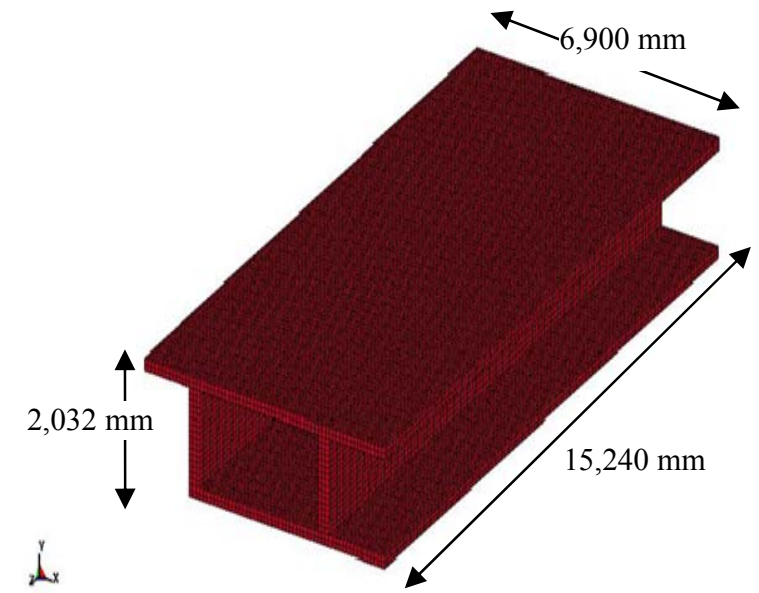

Fig. 1 Isometric showing the dimensions of the quarter of the bridge model.

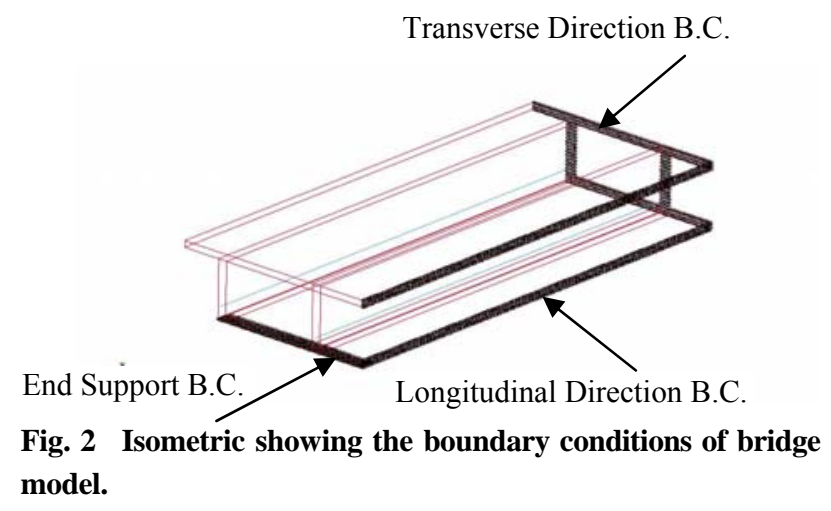

exterior web. Three different cases were studied: the first case was assumed to sterngthened the lower surface of the bridge deck at the midspan section, the second case was to strengthen the upper surface, and the last case was done bybplacing the CFRP on both sides of the bridge deck as shown in Fig. 3.

The concrete was modeled using the hexagonal solid element with one point of integration and the WINFRITH CONCRETE material model was assigned to these elements. The WINFRITH_CONCRETE model is capable of capturing the concrete behaviour under impulsive loads [9]. The conventional and pre-stressed steel was modeled as discrete elements immersed in the concrete mesh taking the advantage of the coupling (constrained) between them using the LAGRANGE_IN_SOLID command available in LS-DYNA. All the steel reinforcement and the pre-stressed strands material were modeled using the PLASTIC_KINEMATIC model. The damping effect used in all the analysis cases was a $2 \%$ modal damping ratio, although the damping has a very little effect on structures subjected to blast loads. The effect of the gravity loads as an initial stress or preload was taken into consideration utilizing the DYNAMIC RELAXATION option available in LS-DYNA.

The CFRP laminates were modeled using the material model COMPOSITE_DAMAGE available in LS-DYNA with optional brittle failure for composites can be defined. By using the user defined integration rule, which is given in LS-DYNA by INTEGRATION_SHELL, the consitiutive constants can vary through the shell thickness. Lamination theory was applied to correct the assumption of constant shear strain across the thickness. The interlaminate bond was assumed perfect with no slippage allowed between the element layers. The three layers were assumed oriented at angles equal to $0^{\circ}, 90^{\circ}$, and $0^{\circ}$ and defined in the SECTION_SHELL card. The properties of the CFRP were derived using the software CADEC-Computer Aided Design Environment for Composites [10]. Table 
1 shows the properties of CFRP used in this study. Fig. 3 shows the finite element mesh of quarter bridge model and the CFRP on the top and bottom faces. The width of the carbon fiber sheets were taken as $1,219 \mathrm{~mm}$ for the quarter model as shown in Fig. 3.

\section{Model Validation}

In this simulation, the blast load was assumed above the bridge deck. The load command defines an air-blast function for the application of pressure loads due to explosives [8]. This option calculates the pressure values when used with the LOAD_SEGMENT command with these segments normal pointing toward the charge. The maximum predicted reflected pressure [11] is compared to the values obtained from LS-DYNA as shown in Fig. 4.

The calculated pressure from LS-DYNA was measured at the nearest element to the ignition point which is considered as a reflected pressure. The minimum and maximum differences between the maximum predicted pressure values using TM5-1300 and LS-DYNA were $8.7 \%$ and $30 \%$ respectively, which gave good prediction of the reflected pressure over bridge deck.

Table 1 CFRP properties.

\begin{tabular}{lllll}
\hline $\begin{array}{l}\text { Material } \\
\text { Type }\end{array}$ & $v$ & $\begin{array}{l}\text { Thickness } \\
{[\mathrm{mm}]}\end{array}$ & $\begin{array}{l}\mathrm{E} \\
\mathrm{MPa}\end{array}$ & $\mathrm{G}$ \\
\hline & $v_{11}=0.22$ & & $\mathrm{E}_{11}=62,100$ & $\mathrm{G}_{12}=3,270$ \\
CFRP & $v_{13}=0.22$ & 1.1 & $\mathrm{E}_{22}=4,830$ & $\mathrm{G}_{12}=3,270$ \\
& $v_{23}=0.47$ & & $\mathrm{E}_{33}=4,830$ & $\mathrm{G}_{12}=1,860$ \\
\hline
\end{tabular}

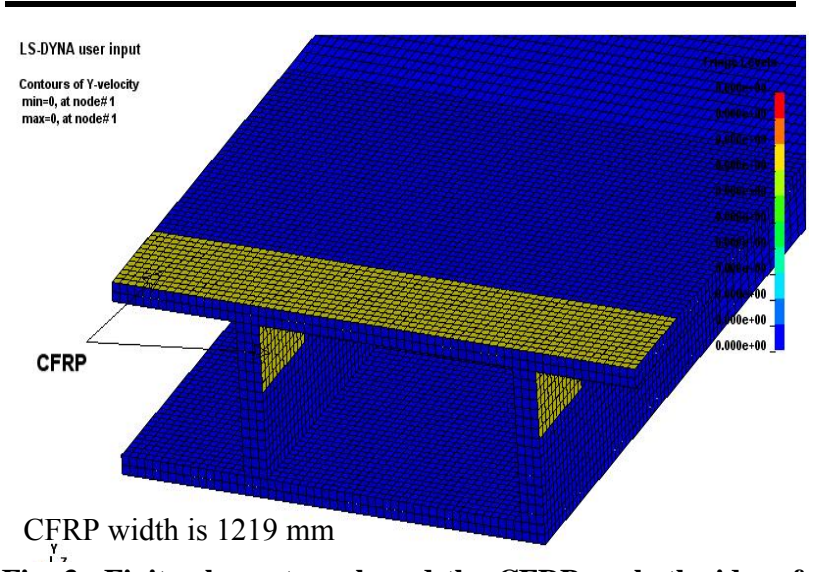

Fig. 3 Finite element mesh and the CFRP on both sides of the deck and part of the web, the shown section is half-model.

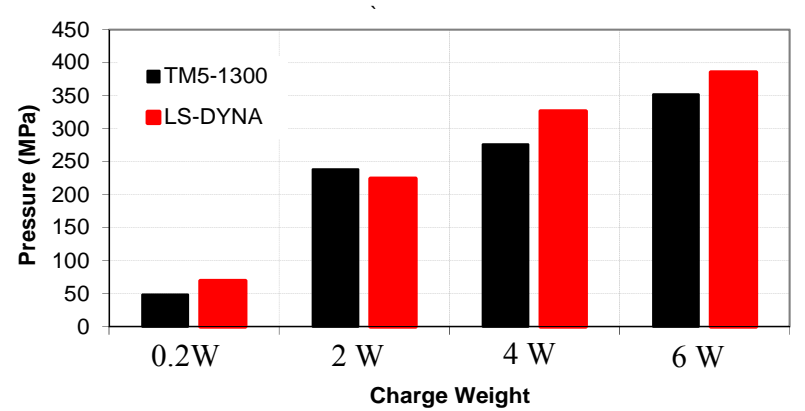

Fig. 4 Comparison between the TM5-1300 and LS-DYNA in predicting the reflected pressure.

A series of tests of retrofitted and normally reinforced concrete slabs were conducted by [12] to study the blast resistance of NRC slabs (normally reinforced concrete) retrofitted by CFRP. The slabs were strengthened by placing the FRP sheets on the top surface of the slabs where it faces the detonation point. The displacement was measured using LVDTs at the centre point of each slab.

The concrete specimens as shown in Fig. 5 were reinforced in both faces of the slabs. All the slabs were $1,000 \mathrm{~mm} \times 2,000 \mathrm{~mm}$, the thickness of the slabs was $100 \mathrm{~mm}$ with concrete cover from both faces equal to $10 \mathrm{~mm}$. The slabs were normally reinforced with a steel mesh spaced at $100 \mathrm{~mm}$ in the major bending direction and $200 \mathrm{~mm}$ in the minor bending direction. The concrete compressive strength was taken $39.5 \mathrm{MPa}$ and Young's modulus was $28.3 \mathrm{Gpa}$. The yield stress of the steel mesh was $600 \mathrm{Mpa}$ and the Young's modulus was 200 Gpa.

The used CFRP was made of pultruded plates and bonded externally on the compression face with a thickness of $2.8 \mathrm{~mm}$ as shown in Fig. 5. Two plates of CFRP were used, the width of each one was $240 \mathrm{~mm}$ running along the whole length of the specimen. In the numerical analysis, the CFRP sheets were as a single layer. Fig. 6 shows the finite element model with the reinforcement and the CFRP plates.

Table 2 summarizes the results of the different explosive sizes, the standoff distances, and the maximum displacement given by $\mathrm{Wu}$ et al. [12]. The predicted displacements of the slabs using LS-DYNA is also shown in Table 2. The NRC-1 and NRC-2 


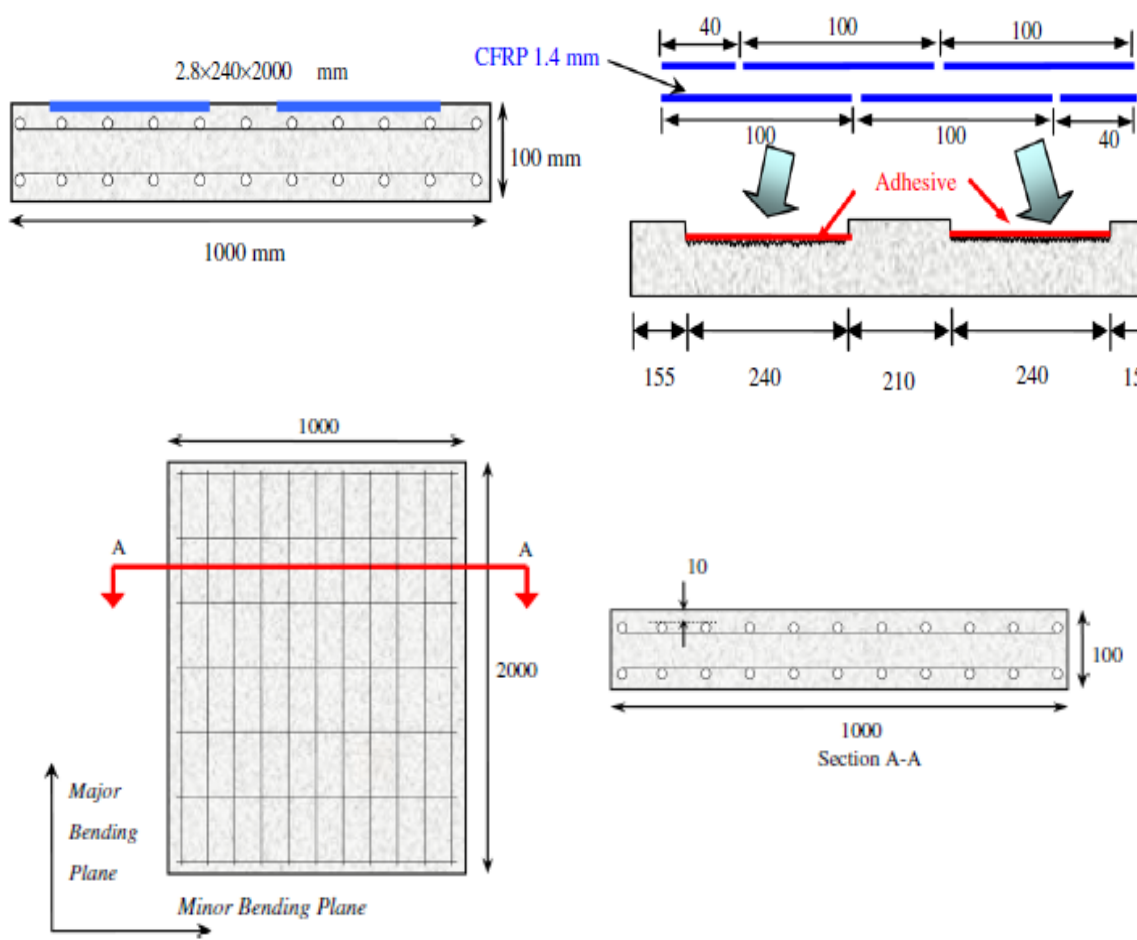

Fig. 5 The reinforced concrete slab dimensions with reinforcement, Geometry and dimensions of the retrofitted slabs [12].

Table 2 Summary of the experimental and numerical comparisons.

\begin{tabular}{|c|c|c|c|c|c|c|}
\hline Test No. & Explosive Size. g & Standoff Distance, m & $\begin{array}{l}\text { Maximum Experimental } \\
\text { Displacement, } \mathrm{mm}\end{array}$ & $\begin{array}{l}\text { Maximum } \mathrm{Nu} \\
\text { Displacement, } \mathrm{mm}\end{array}$ & $\begin{array}{l}\text { Difference } \\
\text { FE/Exp. }\end{array}$ & Ratio \\
\hline NRC-1 & 1,007 & 3,000 & 1.9 & 1.55 & 0.81 & \\
\hline NRC-2 & 8,139 & 3,000 & 10.5 & 13 & 1.27 & \\
\hline RET-1 & 1,044 & 1,500 & 3.7 & 2.9 & 0.73 & \\
\hline RET-2 & 5,083 & 920 & 50.6 & 50 & 0.98 & \\
\hline
\end{tabular}

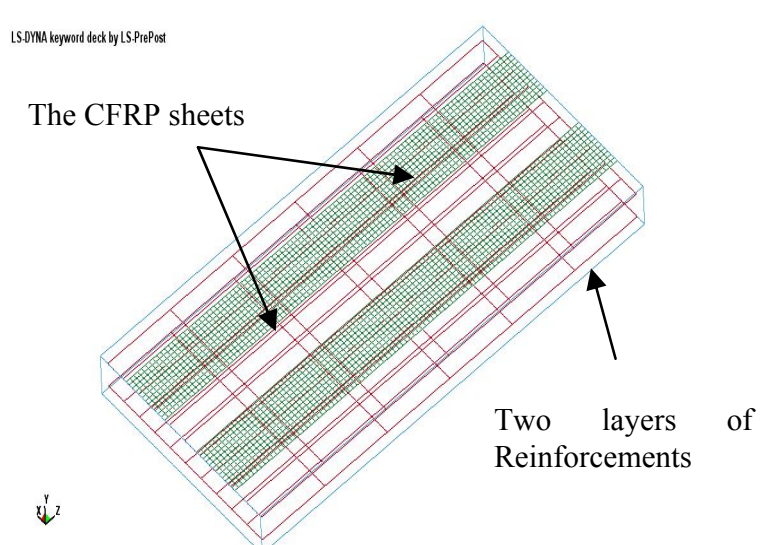

Fig. 6 Finite element mesh of the modeled CFRP.

represent the normally reinforced concrete specimens which are tested under different blast loads. The RET-1 and RET-2 represent the retrofitted slabs using the CFRP and also were tested under different blast loads.
It can be seen from Table 2 that the results of the numerical simulation are close to the experiments. It is shown from Table 2 that the minimum and maximum difference between the numerical and the experimental analyses are $1.18 \%$ and $9.52 \%$ respectively. The first specimen did not show any type of failure because the standoff distance was longer than the others. But in the case of slab RET-2, which was subjected to a $5 \mathrm{~kg}$ explosives at standoff distance of $0.92 \mathrm{~m}$, it is noticed that there is no damage or crushing of the slab but deboning of the CFRP was predicted and the same response occurred in the numerical results. Also LS-DYNA predicted some cracks at the supports and at the mid-span similar to what was observed in the field test as shown in Fig. 7. 

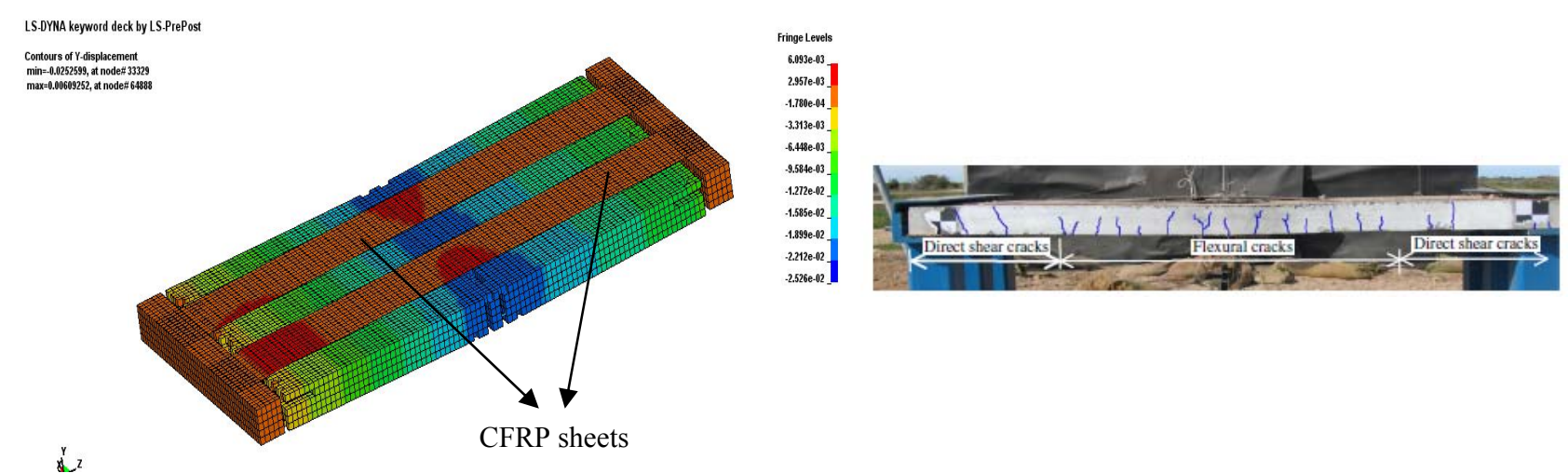

Fig. 7 Comparison between the finite element and the experimental results.

\section{Results and Discussion}

Fig. 8 shows the total energy of the bridge before and after using the CFRP material under blast load of $10 \mathrm{~W}$. It can be seen that the maximum energy was reached at time 0.004 seconds and the values are $2.04 \times 10^{8}$ and $1.22 \times 10^{8} \mathrm{lb}$-in for the case of using CFRP on top, bottom and the reference model, respectively. Using the CFRP laminates in strengthening the top and the bottom surfaces of the bridge deck was effective and it increased the total energy of the bridge deck by $167 \%$.

The strengthening of the box girder bridge deck using CFRP in three ways (on top surface, on bottom surface, and on the top and bottom surfaces) has a significant effect on the velocity time history.

As shown in Fig. 9, the vertical velocity profile for the three strengthening cases of the box girder deck using CFRP, was compared to the reference case, which does not have any strengthening techniques.

All the studied cases were for blast load of $10 \mathrm{~W}$ and placed over the exterior web of the model. The vertical

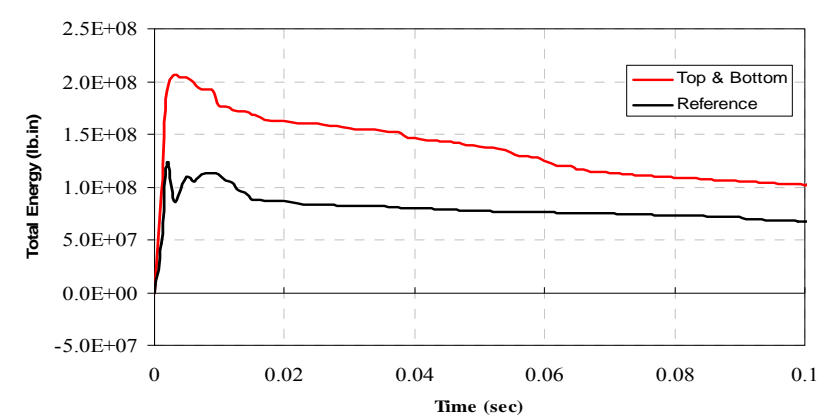

Fig. 8 Total Energy for the bridge deck for the control and the strengthened cases.

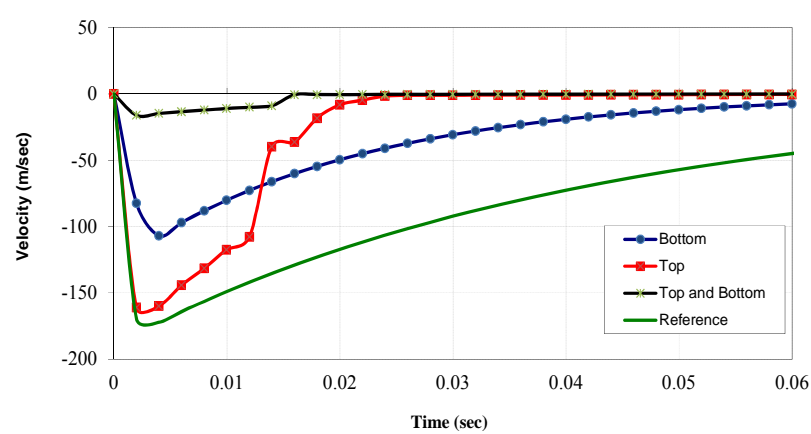

Fig. 9 Velocity profile for the strengthened bridge deck under.

velocity for all the shown cases in Fig. 8 are the same until about 0.001 seconds from the detonation time, and then a divergence occurred to the profile behavior.

From the damage point of view, Table 3 shows the effect of strengthening the bridge deck using the CFRP in three methods. The maximum velocity was traced at the nearest element under the detonation point. The damage size is measured as the equivalent area of the formed crater. As shown in Table 2, there is a significant effect on decreasing the crater size especially when the carbon fiber was used on the bottom and the top faces of the concrete deck.

For the blast load $10 \mathrm{~W}$, it is noticed that the crater size decreased from 5.26 in to $3.71 \mathrm{~m}$ which indicates $60 \%$ decrease in the damage size. Similarly, for the load $30 \mathrm{~W}$, it is noticed that the crater size decreased from a global failure case to 196 inches which indicates that CFRP strengthening is effective for these types of decks. The CFRP did not prevent the damage to the deck but it decreased the catastrophic action of close-in detonations. 
Table 3 Velocity time history and damage size of the strengthened cases using CFRP.

\begin{tabular}{llll}
\hline Case & Charge Size $(\mathrm{kg})$ & Maximum Velocity $(\mathrm{m} / \mathrm{sec})$ & Damage Size/Crater Diameter $(\mathrm{m})$ \\
\hline Control & $10 \mathrm{~W}$ & 88.39 & 5.26 \\
Control & $30 \mathrm{~W}$ & 172.2 & 10 \\
Bottom & $10 \mathrm{~W}$ & 113.03 & 3.86 \\
Bottom & $30 \mathrm{~W}$ & 106.93 & 5.89 \\
Top & $10 \mathrm{~W}$ & 112.27 & 4.03 \\
Top & $30 \mathrm{~W}$ & 19.45 & 5.1 \\
Top and Bottom & $10 \mathrm{~W}$ & 112.27 & 3.71 \\
Top and Bottom & $30 \mathrm{~W}$ & 27.68 & 4.97 \\
\hline
\end{tabular}
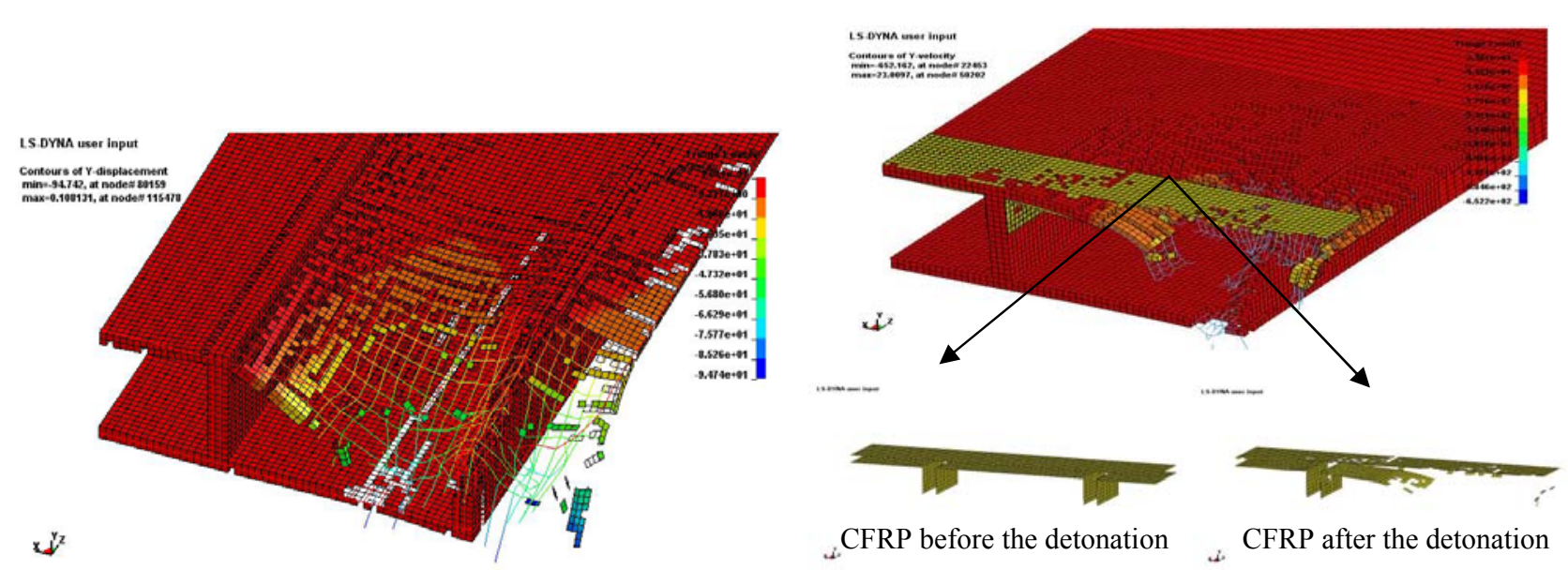

Fig. 10 CFRP before and after the detonation at the same charge weight (the shown sections are half of the model).

From the analysis of LS-DYNA results it is noticed that using CFRP absorbed some energy after the detonation time by few seconds and that appeared in the decrease of the damage size. But after the detonation the CFRP reached its maximum tensile strength rapidly as it behaved as a brittle material. The sheets were destroyed and a debonding occurred, then the remaining energy was transferred to the concrete deck resulting in cracking and damage process to start. Fig. 10 shows the damage suffered by the bridge deck in the case of top and bottom strengthening under $10 \mathrm{~W}$ loading. It is seen that using CFRP on the top and the bottom faces of the deck decreases the velocity of the nearest element to the detonation by $50 \%$ which means that this technique is performing the best among the three, and could economically decrease the damage to these types of bridges.

\section{Conclusions}

This paper investigates the local and the global response of pre-stresses concrete box girder bridges under blast loads. The study was conducted using the dynamic explicit code LS-DYNA. The numerical results were evaluated using experimental filed data published on strengthened concrete slabs. The box girder bridge was strengthened using CFRP on the top surface, on the bottom surface, and on both sides of the concrete deck. The results show that the CFRP offered extra resistance to the deck in terms of absorbing more energy and that can be measured by the local damage of the experienced by the concrete deck before and after adding the CFRP. The damage size significantly decreased when the CFRP was used on the top and the bottom surfaces; however the CFRP material was failed in a sudden behaviour. More experimental 
investigation is needed for box girder bridges under near field detonations.

\section{References}

[1] E. P. Small, Condition of the nation's highway bridges, TR News, Transportation Research Board 194 (1998) 3-8.

[2] C. Kasidit, C. S. Yim and T. H. Miller, Nonlinear finite element analysis of FRP-strengthened reinforced concrete bridge, Journal of Bridge Engineering 11 (1) (2006) 21-32.

[3] R. C. Betra and N. M. Hassan, Blast resistance of unidirectional fiber reinforced composites, Composites Engineering (part B) 39 (2008) 513-536.

[4] P. A. Buchan and J. F. Chen, Blast resistance of FRP composites and polymer strengthened concrete and masonry structures - A state-of-the-art review, Composites Engineering (part B) 38 (2007) 509-522.

[5] P. Alagusundaramoorthy, I. E. Harik, M. Asce and C. C. Choo, Structural behaviour of FRP composites bridge deck panels, Journal of Bridge Engineering 11 (4) (2006) 384-393.

[6] M. K. Mosalam and A. S. Mosallam, Nonlinear transient analysis of reinforced concrete slabs subjected to blast loading and retrofitted with CFRP composites, Composites and Structures (Part B) 32 (2001) 623-636.
[7] H. J. Kim, S. B. Kim, J. H. J. Kim and K. J. Byun, Analytical study of finite element models for FRP retrofitted concrete structure under blast loads, International Journal oF Damage Mechanics 18 (5) (2009) 461-490.

[8] Livermore Software Technology Corporation, LS-DYNA Nonlinear Dynamic Analysis of Structures, Version 971, Livermore, California, 2007.

[9] B. J. Broadhouse, The winfrith concrete model in LS-DYNA3D, Structural Performance Department, AEA Technology, Winfrith Technology Center, 1995.

[10] E. Barber, CADEC-Computer Aided Design Environment for Composites, University of West, Virginia, 1995.

[11] TM 5-1300, Structures to Resist the Effects of Accidental Explosions (with Addenda), Department of the Army Technical Manual, Department of the Navy Publication (NAVFAC P-397), Department of the Air Force Manual (AFM 88-22), Washington, D.C., 1990.

[12] C. Wu, D. J. Oehlers, J. Rebentrost, J. Leach and A. S. Whittaker, Blast testing of ultra-high performance fiber and FRP-retrofitted concrete slabs, Engineering Structures 31 (2009) 2060-2069. 